\title{
A Importância de uma Ampla Interação entre Universidades e os Habitats de Inovação
}

\author{
The Importance of a Wide Interaction Between Universities and \\ Innovation Habitats
}

\author{
Bruno Teixeira Maldonado ${ }^{1}$ \\ Marcelo Farid Pereira ${ }^{1}$ \\ ${ }^{1}$ Universidade Estadual de Maringá, Maringá, PR, Brasil
}

\begin{abstract}
Resumo
Como instituições voltadas ao ensino e à pesquisa, as universidades possuem um papel fundamental na criação e no desenvolvimento do conhecimento e da tecnologia necessários para as atividades de inovação. Em vista da importância desses elementos para o desenvolvimento socioeconômico, torna-se essencial a interação entre a universidade e o setor empresarial. Entretanto, dada as suas especificidades e as naturezas diferentes de cada um, observa-se uma série de obstáculos para o desenvolvimento dessa interação. O objetivo deste artigo é averiguar como é possível superar tais obstáculos no atual contexto do sistema de inovação nacional, sustentado pelo estudo bibliográfico do tema, do modelo da tríplice hélice e dos habitats de inovação. O estudo, ao fim, enfatizou a importância dos habitats de inovação para dar suporte a essa interação e promover a interação dos agentes da tríplice hélice, suprindo as lacunas institucionais existentes entre estes para efetivar um ambiente de inovação.
\end{abstract}

Palavras-chave: Tríplice Hélice. Universidades. Habitats de Inovação.

\begin{abstract}
As institutions focused on teaching and research, universities play a key role in creating and developing the knowledge and technology needed for innovation activities. Given the importance of these elements for socioeconomic development, the interaction between the university and the business sector become essential. However, given their specificities and the different natures of each, there are a number of obstacles to the development of this interaction. The aim of this paper is to investigate how it is possible to overcome such obstacles in the current context of the national innovation system, supported by the bibliographical study of the theme, the triple helix model and the innovation habitats. Finally, the study emphasized the importance of innovation habitats to support this interaction, in order to promote the interaction of triple helix agents, filling the institutional gaps between them, to effect an innovation environment.
\end{abstract}

Keywords: Triple Propeller. Universities. Innovation Habitats.

Área Tecnológica: Desenvolvimento. Inovação Tecnológica.

\section{Introdução}

A inovação e a tecnologia se mostram cada vez mais importantes e atreladas ao desenvolvimento socioeconômico na medida em que criam ou melhoram bens e serviços, ou tornam sua produção mais eficiente e com maior valor agregado, podendo abrir novos mercados $e$ 
estabelecer vantagens competitivas. Por esse motivo, é natural que mereçam destaque nas políticas socioeconômicas estatais.

Todavia, o mercado é cada vez mais dinâmico, enquanto o conhecimento e a tecnologia encontram-se cada vez mais complexos, aumentando a necessidade de interação e de atuação conjunta entre empresas e demais organizações inseridas nesse contexto para que seja possível adquirir e aplicar o conhecimento especializado, entendimento esse já consolidado no próprio Manual de Oslo, documento editado pela Organização para a Cooperação e Desenvolvimento Econômico (OCDE) (FINEP, 2005).

Dadas essas circunstâncias, as universidades passam a ter um papel importante no ambiente interativo junto às empresas, eis que, além de formadoras de mão de obra especializada por meio de suas atividades de ensino, também possuem a pesquisa em sua gênese e a infraestrutura necessária para realizá-la, sendo então as detentoras e produtoras naturais de novos conhecimentos.

Para que esse conhecimento seja transformado em produtos e serviços a serem inseridos no mercado, é essencial que as universidades possuam uma interação ampla junto às empresas interessadas em aplicá-los, sendo que nesse contexto surgiu então o modelo da Tríplice Hélice, reconhecido internacionalmente nos estudos sobre inovação (OSINSKI et al., 2018), que propõe a interação contínua entre a universidade, a indústria e o Estado com intuito de promover o fomento à atividade inovativa.

Todavia, ante a natureza e as diferentes finalidades de cada uma dessas partes, constatam-se certos obstáculos que dificultam essa interação. Afinal, universidades e empresas lidam com a pesquisa e o conhecimento de forma diversa uma da outra, sendo que as primeiras, como instituições de ensino, ainda precisam dividir sua infraestrutura e o corpo de funcionários com as atividades voltadas para a formação de mão de obra e de ampliação da base de conhecimento da sociedade.

Para superar tais obstáculos e ampliar as interações entre os diferentes agentes inovadores, há que se observar a importância dos habitats de inovação, que são ambientes de cooperação formados justamente com essa finalidade, capazes de suprir as lacunas institucionais verificadas em um sistema de inovação em desenvolvimento, sendo esse o enfoque deste trabalho.

Para tanto, o presente estudo estruturou-se inicialmente abordando o modelo da Tríplice Hélice e a importância da interação dos agentes que a compõem em um contexto social e econômico no qual o conhecimento e a inovação são cada vez mais relevantes para o desenvolvimento.

Em seguida, buscou-se analisar a situação das universidades, principalmente as públicas, onde se encontra a maior parte da infraestrutura de pesquisa do Brasil, e quais os maiores obstáculos existentes que se opõem à interação destas e do setor empresarial.

Por fim, em vista desses entraves, a parte final deste documento enfoca na importância dos habitats de inovação como espaços nos quais é possível superar os obstáculos por meio da cooperação conjunta dos agentes da Tríplice Hélice e de organizações híbridas ali presentes, de modo que agentes diferentes possam suprir as lacunas existentes. 


\section{Metodologia}

A metodologia utilizada para subsidiar o presente estudo se pautou na pesquisa bibliográfica, ou seja, por meio do levantamento de pesquisas anteriores, presentes em livros, artigos, teses e afins (SEVERINO, 2007, p. 122), com intuito de observar a importância das universidades para o funcionamento da tríplice hélice, as dificuldades inerentes destas como agentes fomentadores da inovação e a importância das organizações híbridas nesse contexto, visando a entender a importância que estas últimas possuem em uma sociedade e em um sistema econômico cada vez mais pautados no conhecimento. Ainda, dentro dessa pesquisa, utilizou-se os dados levantados por Turchi e Arcuri (2017) no ano de 2015, que se deu pela aplicação de questionários junto a coordenadores das principais infraestruturas públicas de pesquisa no Brasil para descobrir quais os maiores obstáculos encontrados no que se refere à interação entre as instituições de pesquisa brasileiras e as empresas.

\section{Resultados e Discussão}

Em vista das constantes mudanças no ambiente tecnológico internacional que se intensificaram no final do século XX com a introdução de uma variedade de inovações na economia e nos processos produtivos, destacando-se as tecnologias de informação e comunicações, associadas a um movimento denominado "globalização", que trouxe novas possibilidades comerciais com novos mercados, observou-se uma intensificação da competição entre empresas e até mesmo entre países (CASSIOLATO, 1999).

A partir de então, a inovação tecnológica decorrente da produção de conhecimento e da sua relação com a atividade econômica ganha cada vez mais importância. Eis que essa mesma inovação passa a ser de suma importância para garantir o aumento da competitividade empresarial e o desenvolvimento socioeconômico de uma localidade.

Todavia, a intensificação das mudanças tecnológicas contribui para que o mercado se torne cada vez mais dinâmico, ao passo que a ciência e a tecnologia se encontram cada vez mais complexas, demandando, por sua vez, mais conhecimentos especializados. Por causa disso, aumenta a necessidade de interação entre empresas que pretendem inovar e fazer uso de novas tecnologias junto às demais organizações que lidam com esse conhecimento, entendimento este já consolidado no próprio Manual de Oslo (FINEP, 2005), documento editado pela Organização para a Cooperação e Desenvolvimento Econômico (OECD).

Desse modo, verifica-se que a "[...] transferência tecnológica tem se tornado um fator determinante para o desenvolvimento econômico, e não tem chamado apenas a atenção de acadêmicos, mas também de agentes governamentais e empresários" (MANSANO; PEREIRA; PARRÉ, 2016, p. 5); sendo a transferência tecnológica o processo pelo qual o detentor de um conhecimento o passa para outro, com exclusividade ou não, para que este faça uso desse conhecimento.

Assim, é comum que surjam aglomerações produtivas entre empresas e instituições que atuem no mesmo setor com intuito de obter vantagens competitivas conjuntas, os chamados Arranjos Produtivos Locais. Entretanto, esses arranjos, por si só, não são garantia de sucesso na implementação da inovação, que está suscetível a diversas variáveis, como a capacidade de 
investimento na pesquisa $e$ implementação de inovação, bem como a organização do setor $e$ do ecossistema de inovação no qual a aglomeração produtiva se encontra (TERRA et al., 2018).

Com o propósito de identificar a fonte do desenvolvimento socioeconômico, baseado em conhecimento, e os protagonistas de um sistema de inovação, para aumentar a interação entre estes e desenvolver uma estratégia de inovação eficiente, surgiu o modelo da Tríplice Hélice, o qual é reconhecido internacionalmente nos estudos sobre inovação (OSINSKI et al., 2018).

\subsection{Da Tríplice Hélice}

A abordagem proposta pela Tríplice Hélice é a de que a geração da inovação em uma sociedade baseada no conhecimento se dá por meio da interação entre a universidade, a indústria e o Estado (TERRA et al., 2018), pois cada um desses agentes (ou hélices) possui uma função dentro de um contexto organizacional.

Vale destacar que, conforme apontam Etzkowitz e Zhou (2017), o Estado, a indústria e a dinâmica são os elementos clássicos das parcerias público-privadas e são reconhecidos como importantes dentro da organização da sociedade desde o século XVIII, de forma que a Tríplice Hélice traz uma nova luz ao papel das universidades, já que as universidades contribuem como provedoras do ensino e de pesquisa e, ainda, passam a ser geradoras de novas empresas, produtos e serviços. Afinal, segundo os citados pesquisadores, com a superação da sociedade industrial pela era do conhecimento, o conhecimento avançado e especializado passa a ser aplicado com mais frequência a usos práticos. Assim, a aproximação das instituições responsáveis por gerá-los permite que conhecimento possa ser transformado em atividade econômica.

Vale ressaltar que a aproximação e a realização de ações coordenadas entre o governo, a estrutura produtiva e a estrutura científica e tecnológica não foram novidades, já que tal proposta foi feita por Jorge Sábato e Natalio Botana na década de 1960, no que ficou conhecido como Triângulo de Sábato (PRESTES et al., 2017). Entretanto, diferentemente do Triângulo de Sábato, a Tríplice Hélice propõe uma estrutura organizacional diferente, helicoidal, inspirada na dupla hélice da descrição do DNA, possibilitando diversas formas de interação e de cooperação entre a universidade, a empresa e o governo, as quais a estrutura triangular não seria capaz de expressar (IPIRANGA; HORA, 2012).

Tal fato se dá porque esse modelo propõe um processo dinâmico para fomentar a inovação constante da qual os detentores do conhecimento científico fazem uso, a fim de que possam gerar produtos e serviços novos a serem inseridos no mercado e passam a integrar o debate sobre as potencialidades de sua localidade no âmbito da inovação. Nesse sentido, é clara a lição de Etzkowitz e Zhou (2017, p. 30), valendo citar:

A Hélice Tríplice é um processo dinâmico para a inovação interminável que se vale dos três espaços da Hélice Tríplice: conhecimento, consenso e inovação. Quando cientistas ou outros se apropriam do conhecimento científico com o intuito de gerar renda, a própria ciência deixa de ser um processo cultural que consome o excedente da sociedade e se torna uma força produtiva que gera novos rendimentos a partir de um aspecto da cultura. Quando os representantes da universidade, da indústria e do governo, assim como outros protagonistas, são convocados para discutir os problemas e potencialidades regionais, pode nascer uma nova dinâmica de inovação e empreendedorismo. Quando esses espaços de "conhecimento" e "consenso" se unem, o palco está pronto para a 
adaptação e invenção de novas metodologias para o desenvolvimento econômico $e$ social baseado no conhecimento.

Embora a interação entre os agentes (ou hélices) seja dinâmica e, até mesmo, variável, dependendo da localidade a ser analisada, Ipiranga e Hora (2012, p. 21) ressaltam as atribuições de cada um, competindo ao Estado, primeiramente, a elaboração e a implementação de políticas públicas voltadas ao incentivo do desenvolvimento científico e tecnológico, às universidades $e$ aos demais agentes da infraestrutura científica e tecnológica a geração de conhecimentos e capital humano especializado, bem como o apoio técnico e estrutural na geração da inovação, enquanto ao setor produtivo, composto de empresas e da indústria, compete a implementação da inovação por meio da transformação do conhecimento em produtos e serviços.

Constata-se, portanto, que o papel das universidades e das demais instituições de pesquisa passou a ganhar uma nova dimensão, para além do fornecimento de mão de obra qualificada. Também passaram também a ser indutoras da inovação por meio da pesquisa e da geração de conhecimento, agindo junto à indústria e às empresas, a fim de desenvolver e de implementar novos produtos e serviços, ganhando um papel relevante para o desenvolvimento de onde se encontram inseridas. Em outras palavras:

A universidade é o princípio gerador das sociedades fundadas no conhecimento, assim como o governo e a indústria são as instituições primárias na sociedade industrial. A indústria permanece como o ator-chave e lócus de produção, sendo o governo a fonte de relações contratuais que garantem interações estáveis e o intercâmbio. A vantagem competitiva da universidade em relação a outras instituições de produção do conhecimento são seus estudantes. O fluxo contínuo de admissão e graduação de alunos traz o aporte de novas ideias, em contraste com as unidades de pesquisa $e$ desenvolvimento de laboratórios de empresas e do governo, que tendem a se ossificar, perdendo o "fluxo de capital humano" que é constituído na universidade. (ETZKOWITZ, 2009 apud FERREIRA, 2018, p. 30)

Todavia, para que estejam habilitadas a desempenhar tal papel, enquanto estão integradas na Tríplice Hélice, as universidades devem possuir um ambiente institucional favorável para tanto, o que faz surgir novos desafios no que se refere a sua estrutura, organização e ambiente, conforme se verá a seguir.

\subsection{Das Universidades Públicas e sua Interação na Tríplice Hélice}

Como já retratado, por causa dos avanços tecnológicos e do advento do conhecimento e da inovação como elementos fundamentais para fomentar a competitividade, as empresas e o setor produtivo como um todo passaram a ver como importante a interação junto às instituições voltadas para a pesquisa científica e detentoras de conhecimentos especializados.

Segundo bem aponta Fernanda De Negri (2017; 2018), para introduzir novos produtos e serviços no mercado, é necessária a existência de uma base científica com profissionais habilitados, bem como de um ambiente onde eles possam realizar suas pesquisas nos mais variados níveis, da pesquisa básica à pesquisa de ponta, sendo que, consequentemente, a infraestrutura laboratorial é imprescindível no processo de inovação. Nesse sentido, como bem aponta a autora, para o processo de inovação ocorra é necessário que haja "[...] uma infraestrutura laboratorial 
capaz de realizar desde a pesquisa básica até o desenvolvimento e a engenharia de produtos e processos, bem como os ensaios e os testes necessários" (DE NEGRI, 2017, p. 26).

Na legislação pátria, mais especificamente na Lei n. 10.973, de 2 de dezembro de 2004, a qual estabelece medidas de incentivo à inovação e à pesquisa científica e tecnológica no ambiente produtivo, também conhecida também como Lei de Inovação Tecnológica, essas instituições voltadas para a pesquisa científica são definidas como Instituições Científicas, Tecnológicas e de Inovação (ou ICTs).

Tais instituições, segundo o artigo $2^{\circ}$, inciso $V$, da referida lei, são órgãos ou entidades da administração pública direta ou indireta, ou pessoas jurídicas de direito privado sem fins lucrativos, com sede e foro no País, que incluam em sua finalidade institucional a pesquisa básica ou aplicada de caráter científico ou tecnológico ou o desenvolvimento de novos produtos, serviços ou processos.

Em outras palavras, ainda que o modelo da Tríplice Hélice enfatize o papel da universidade, não somente essa instituição pode ser considerada provedora do conhecimento a ser desenvolvido e transferido para o setor produtivo, até porque a interação dos agentes que compõem a Tríplice Hélice é variável de acordo com o local e o contexto em que se encontram. Assim, convém destacar que:

O sistema de inovação dispõe, em vários países, além de universidades, de uma variedade enorme de instituições de pesquisa ou grandes laboratórios, alguns mais voltados à pesquisa básica, outros focados na resolução de problemas concretos da sociedade e do setor produtivo. É assim no caso dos Estados Unidos, com os laboratórios nacionais ligados ao Departamento de Energia e com os National Institutesof Health (NIHs), por exemplo. Também é assim no caso da China, com os laboratórios públicos vinculados à Academia Chinesa de Ciências, que possui institutos de pesquisa nas mais diversas áreas, espalhados em todo o território nacional. Também é assim na Alemanha, com os institutos Max Planck e Fraunhofer, só para citar alguns exemplos. (DE NEGRI, 2018, p. 27)

No que se refere ao cenário brasileiro, todavia, o principal destaque ainda vale para as universidades, principalmente as públicas, onde se encontra a maior parte da infraestrutura de pesquisa do Brasil (DE NEGRI, 2018, p. 65).

Como consequência, passa a ser necessário repensar o papel das universidades, papel que deixa de ser tão somente o de formadoras de mão de obra e de ampliadoras da base de conhecimento da sociedade e passa a ser o de assumir também a função de fomentadoras da inovação e do desenvolvimento socioeconômico (GIMENEZ; BONACELLI; CARNEIRO, 2016, p. 119). Além disso, também é necessário averiguar se as universidades se encontram estruturadas e em condições de assumirem tal papel.

Isso porque, vale destacar, pelo fato de a maior parte das ICTs brasileiras serem universidades, sua infraestrutura e corpo de científico não são voltados somente para a pesquisa visando à inovação, mas também para o ensino e formação de novos profissionais, além de outras atividades administrativas. Ademais, como a maior parte das universidades é pública, elas também encontram obstáculos na burocracia envolvendo processos de compras, assinaturas de contratos e convênios ou de contratações de pessoal, como ressalta Fernanda de Negri (2018, p.71). 
Ainda, há que se notar que, diante das diferentes naturezas entre as instituições de ensino, principalmente as públicas, e as empresas do setor privado, esses dois agentes da Tríplice Hélice acabam abordando a questão da pesquisa e da inovação de forma diversa. Isso pelo fato de as primeiras buscarem produzir, codificar e divulgar seu conhecimento ao maior número de pessoas possível (afinal, sua finalidade, a princípio, é o ensino e a pesquisa como forma de divulgação do conhecimento), enquanto as últimas têm como objetivo proteger seu conhecimento e transformá-lo em mercadoria, visando a obter vantagens competitivas no mercado (TURCHI; ARCURI, 2017).

Por conta desse cenário, convém trazer à baila o estudo realizado por Turchi e Arcuri (2017), a fim de avaliar a interação entre as Instituições Científicas e Tecnológicas (ICTs) públicas e as empresas, que se deu por meio da aplicação de um questionário a coordenadores das principais infraestruturas públicas de pesquisa no Brasil, no ano de 2015.

$\mathrm{Na}$ ocasião, ao analisar o resultado dos questionários, observou-se que, no que se refere aos obstáculos experimentados sobre a gestão da própria universidade, mais de metade dos entrevistados apontaram dificuldades relativas ao tempo gasto na contratação e monitoramento, na qualificação da equipe e no número de pessoal administrativo. Esses três maiores obstáculos, somados ao quarto colocado, que é relativo à experiência da universidade para operacionalizar parcerias com empresas, atestam que essas instituições ainda não se encontram devidamente preparadas e habituadas para atuar junto ao setor produtivo.

Gráfico 1 - Dificuldades com a gestão da universidade (em \%)

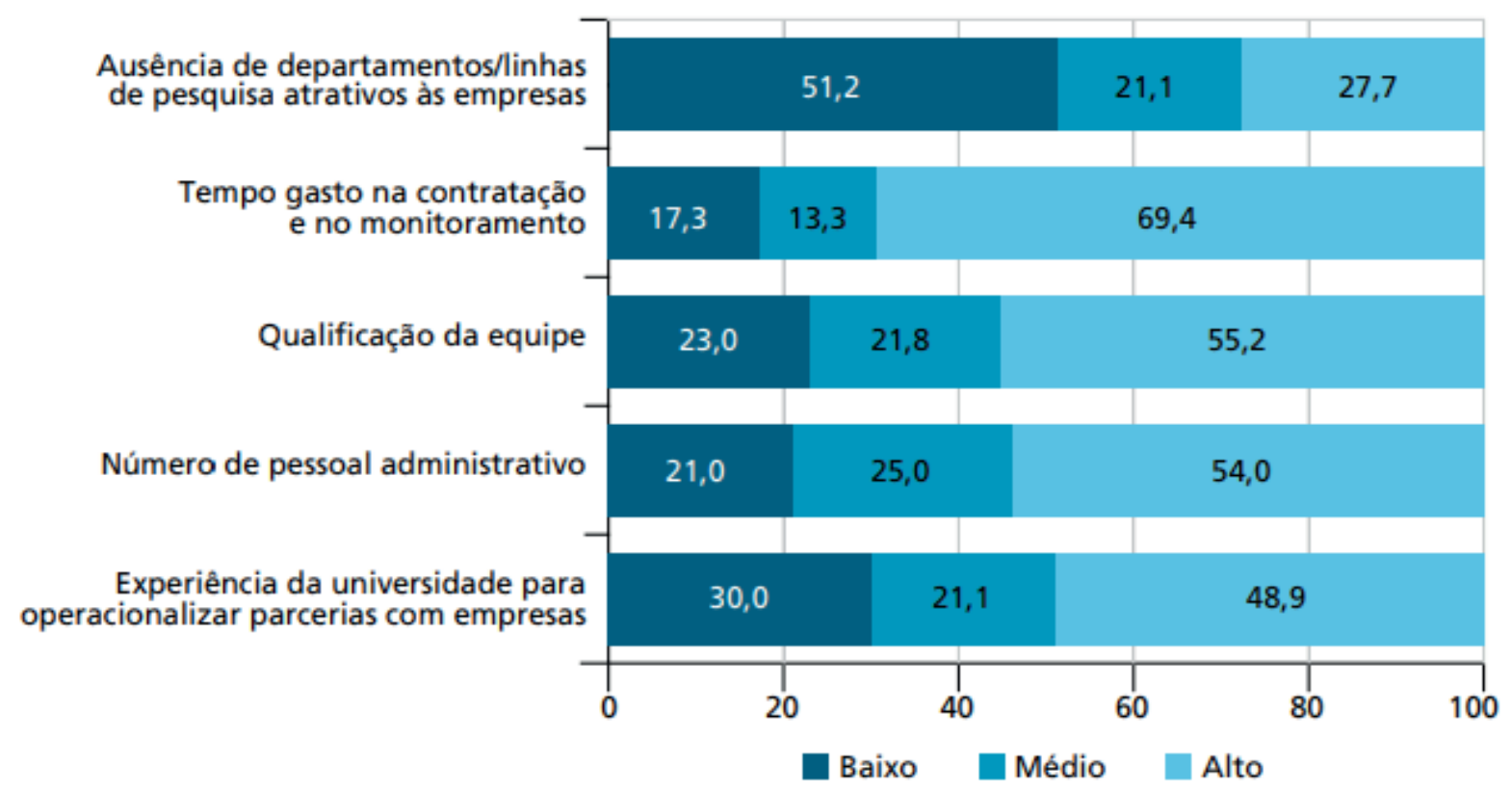

Fonte: Turchi e Arcuri (2017)

$\mathrm{Na}$ mesma pesquisa, no que se refere às dificuldades que os pesquisadores encontraram sobre as condições da infraestrutura da universidade, o maior obstáculo averiguado foi o tamanho da equipe técnica, com larga vantagem sobre as demais opções a serem assinaladas. 
Gráfico 2 - Dificuldades com as condições da infraestrutura (em \%)

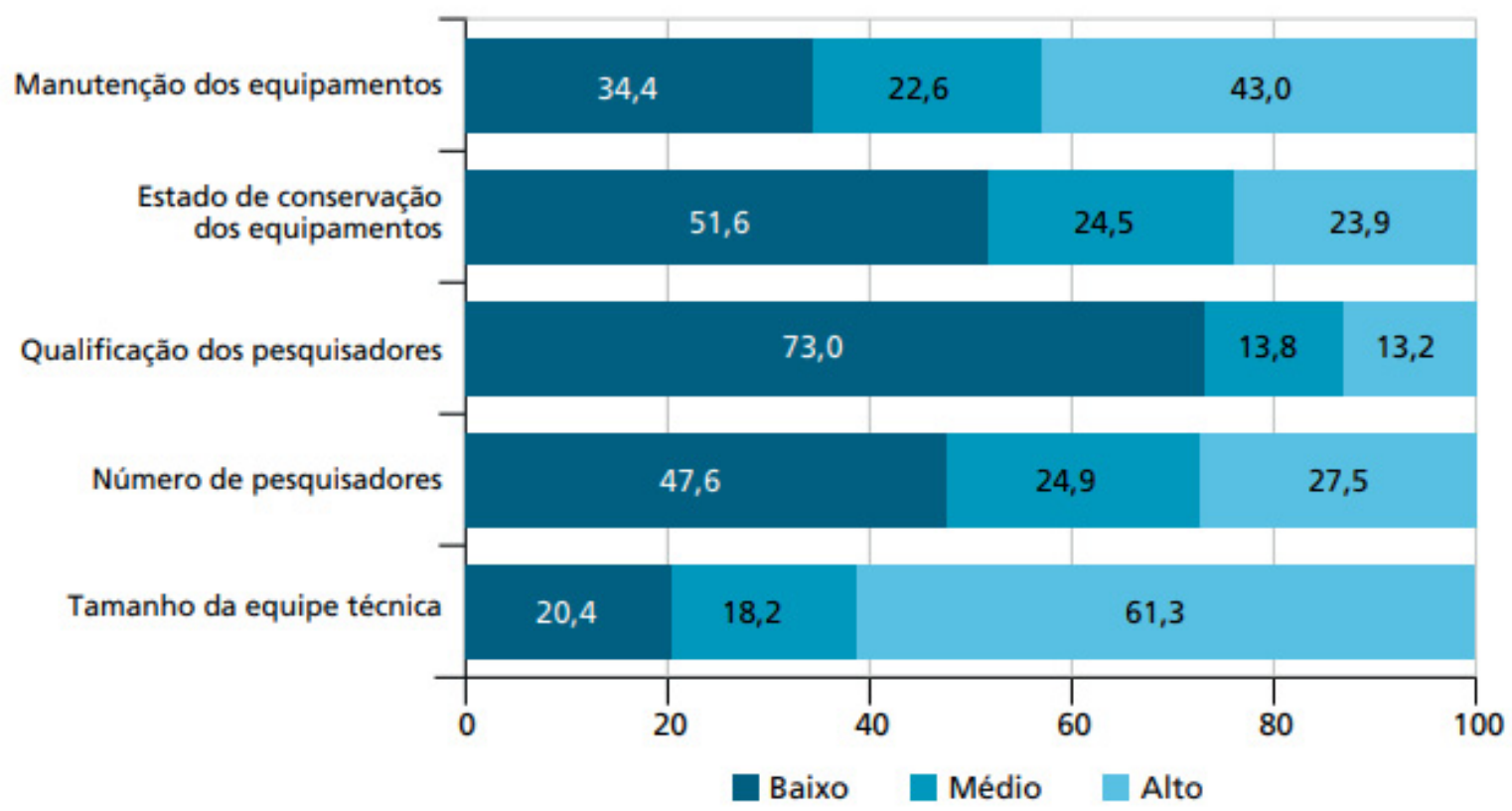

Fonte: Turchi e Arcuri (2017)

Por fim, convém observar que os responsáveis pelos laboratórios que foram entrevistados relataram que a maior dificuldade sobre o relacionamento junto às empresas foi a questão das normas dessas empresas para divulgação de conteúdo da pesquisa, já que, conforme apontado anteriormente, por vezes, divergem da lógica com a qual as instituições de ensino e pesquisa lidam com o conhecimento e o resultado de suas pesquisas, eis que, enquanto as empresas podem prezar pelo sigilo, as universidades priorizam a divulgação do conhecimento.

Gráfico 3 - Dificuldades com a gestão da empresa (em \%)

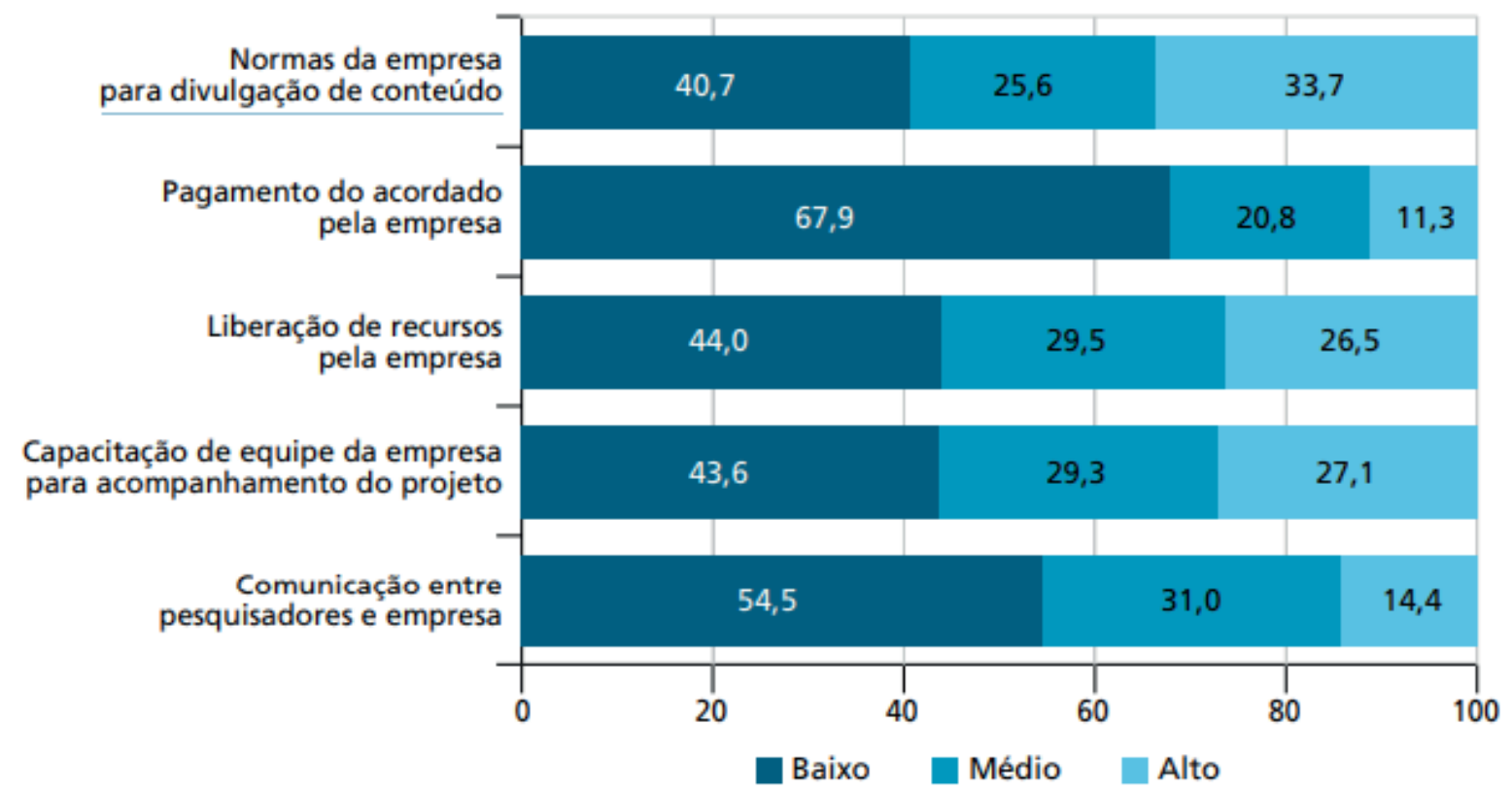

Fonte: Turchi e Arcuri (2017) 
Desse levantamento de dados, é possível depreender que, no que tange às instituições científicas pátrias, há um despreparo em sua estrutura para ampliar suas atividades além do ensino e da pesquisa, pois realizar atividades em conjunto com o setor empresarial e implementar atividades voltadas à inovação perpassa em boa parte pelo quantitativo e pelo preparo de seu pessoal, principalmente no que se refere às questões administrativas.

De outro lado, por sua vez, parte do empresariado vê como os principais obstáculos para realizar parcerias com as universidades a falta de mecanismos de intermediação e de acesso à pesquisa, bem como a ausência de comprometimento com prazos e sigilo de informações e a dificuldade de transferir os resultados das pesquisas para o mercado (CLOSS; FERREIRA, 2012).

Justamente por tais diferenças e pelos obstáculos que as instituições de ensino encontram para se dedicar à inovação, é necessário que se crie um ambiente de confiança e de segurança que facilite a troca de conhecimento e de experiências entre as partes, afinal, como bem salientam Faiadet al. (2016, p. 9), a inovação consiste em um fenômeno sistêmico e interativo. Para construir tal ambiente, por sua vez, faz-se necessário o surgimento de espaços de inovação voltados à troca de conhecimento e ao esforço conjunto das partes, podendo estes serem definidos como habitats de inovação.

\subsection{Da Necessidade dos Habitats de Inovação}

Conforme definem Machado, Silva e Catapan (2016, p. 89-90), habitats de inovação são ambientes voltados ao compartilhamento do conhecimento, por meio do empreendimento com o intuito de promover a inovação, sendo fortalecidos por uma política de promoção da interação entre o governo, as instituições educacionais e as empresas.

Entre os vários conceitos de habitats de inovação fornecidos pela literatura dessa área, convêm observar aquele exarado por Correia e Gomes, ante a sua assertividade e clareza:

Habitats de inovação constituem-se de espaços de aprendizagem coletiva, intercâmbio de conhecimentos, de interação entre empresas, instituições de pesquisa, agentes governamentais para a realização de pesquisas que podem ser transferidas para o setor produtivo, contribuindo para o desenvolvimento econômico de uma cidade, região ou país. (CORREIA; GOMES apud SARTORI, 2017, p. 71)

Assim sendo, pode-se concluir que os habitats de inovação se fazem essenciais para o pleno funcionamento e integração da tríplice hélice:

Os habitats de inovação são espaços diferenciados, propícios para que as inovações ocorram, pois são locus de compartilhamento de informações e conhecimento, formando networking, e permitem minimizar os riscos e maximizar os resultados associados aos negócios. O habitat de inovação permite a integração da tríplice e procura unir talento, tecnologia, capital e conhecimento para alavancar o potencial empreendedor e inovador. (TEIXEIRA et al., 2016, p. 8)

Segundo bem afirmam Etzkowitz e Zhou (2018), tais espaços são variáveis de acordo com o contexto de cada região, sendo compostos por instituições secundárias, ou organizações híbridas, formadas pelo esforço conjunto dos agentes da Tríplice Hélice a fim de promover 
atividades científicas e tecnológicas em busca do desenvolvimento econômico e social. Assim, vale citar dos referidos autores:

Definimos a Hélice Tríplice como um modelo de inovação em que a universidadel academia, a indústria e o governo, como esferas institucionais primárias, interagem para promover o desenvolvimento por meio da inovação e do empreendedorismo. No processo de interação novas instituições secundárias são formadas conforme a demanda, isto é, "organizações híbridas". A dinâmica das esferas institucionais para o desenvolvimento em uma hélice tríplice sintetiza o poder interno e o poder externo de suas interações. (ETZKOWITZ; ZHOU, 2017, p. 24-25)

A título de exemplo, entre tais instituições, ou habitats, pode-se elencar as cidades intensivas em conhecimento, cidades inteligentes, os parques (científicos, tecnológicos, científicos e tecnológicos, de inovação e de pesquisa), centros de inovação, pré-incubadoras, incubadoras, aceleradoras, coworking, markespace e os Núcleos de Inovação Tecnológica; todavia, a rigor não existe uma hierarquia existente entre eles (TEIXEIRA et al., 2016, p. 7).

Com a atuação conjunta desses agentes, sejam públicos ou privados, fruto de uma construção institucional planejada ou mesmo de decisões desarticuladas, visando a impulsionar o progresso tecnológico e a capacidade de inovação de uma localidade tem-se um sistema de inovação, ou sistema nacional de inovação (ALBUQUERQUE, 1996, p. 57).

Justamente com o objetivo de fomentar esse sistema que a legislação pátria, mais especificamente a já citada Lei de Inovação, modificada pela Lei n. 13.243/2016, busca incentivar a interação conjunta entre os agentes da tríplice hélice (artigo $3^{\circ}$ ) e a aproximação desses junto aos habitats de inovação (artigo $3^{\circ} \mathrm{B}$ ).

Entretanto, como já observado, as ICTs pátrias não se encontram plenamente estruturadas para expandirem suas atividades de rotina, eis que sua grande maioria são universidades públicas e já possuem a responsabilidade pelas atividades de ensino e provimento de mão de obra especializada. Por outro lado, o setor empresarial entende que faltam mecanismos de intermediação e de acesso à pesquisa para atuar junto às universidades.

Tais questões acabam por revelar um contexto em que o sistema nacional de inovação não se encontra em plenas condições de promover o desenvolvimento econômico e social pretendido. Essa situação, segundo Felipe (2017, p. 19), pode ocorrer na estrutura institucional de países ainda em desenvolvimento, sendo chamada por ele de lacuna institucional.

O termo lacuna institucional, vale dizer, é de grande clareza para ilustrar esse entrave dentro do modelo da Tríplice Hélice. Afinal, como já apontado, o referido modelo sugere uma estrutura organizacional helicoidal e dinâmica entre os agentes que a compõe visando a sua interação. Assim, a existência da lacuna exprime devidamente a ideia de que a organização vigente entre universidade, empresas e Estado é falha em impulsionar a interação desses objetivando a atividade de inovação.

A presença dessa lacuna, entretanto, não pode agir como um impeditivo na promoção da interação entre os agentes da tríplice hélice, mas sim como uma questão a ser considerada na construção de um sistema nacional de inovação e no momento de elaboração de políticas públicas para sua efetivação. Nesse sentido, versam Johnson e Lundvall (2000, p. 14): 
A development strategy based on an innovation system approach would start by analysing all parts of the economy that contribute to competence building and innovation. It would focus on the linkages and synergies between the parts that form the system as a whole and, especially, it would try to identify the nodal points and crucial learning stimulating linkages. It would also try to identify the missing linkages and interactions; the interactions which for different reasons do not occur thereby reducing the innovation performance of the economy.

Por outro lado, a superação desses obstáculos perpassa também pelos próprios habitats de inovação e seu fortalecimento, os quais podem suprir as lacunas institucionais (FELIPE, 2017, p. 19). Afinal, nos espaços fronteiriços que estes ocupam dentro da tríplice hélice é possível que esferas institucionais diferentes supram as necessidades deixadas pela falta de protagonismo de outra (ETZKOWITZ; ZHOU, 2017, p. 28).

A respeito do tema, Champenois e Etzkowitz (2018) enfatizam que, em um ambiente de integração, os agentes da tríplice hélice podem assumir os papéis uns dos outros, saindo de suas rotinas comuns e visualizando as dificuldades a serem enfrentadas para a formação de um sistema de inovação funcional, ponto a partir do qual é possível que se busque soluções para esses problemas estruturais e que se formem as organizações voltadas a supri-los.

Consequentemente, resta necessária a aproximação constante por parte da universidade, bem como das demais hélices, desses habitats de inovação, ainda que em estágios iniciais, de modo que a ela deve ser incentivada não somente por meio da legislação (como no já citado artigo $3^{\circ} \mathrm{B}$ da lei de inovação), mas também por políticas que efetivem a intenção do legislador.

Tais habitats, por sua vez, principalmente no que se refere à países cujo sistema nacional de inovação se encontra em desenvolvimento, como é o caso do Brasil, também devem receber o apoio público, como explicitado por Arocena e Sutz (2002, p. 17):

Thus, a strategy is sketched for building Innovation Systems in underdeveloped countries that begins with the analysis of the specific features of learning processes and of what really happens at that level. From our point of view, the strategy is based on an actors perspective, stressing the relevance of existing or missing interactions; thus, the results of concrete policies will crucially depend on the attention given to the interests, needs and possibilities of the different actors potentially involved in innovation processes. The strategy is also based on a "bottom-up" perspective. Indeed, the starting point is given by the links, synergies or innovative circuits that really exist, which are considered as lessons, stemming from society itself, as to how to cope with innovation problems in the usually less than friendly context of underdevelopment. They deserve the care a gardener gives to his flowers. Since "interactive learning spaces" can be seen as the "cells" of the innovative tissue, their multiplication and interconnection creates the Innovation Systems from below. Thus, detecting, protecting and promoting such germinal spaces seems a central chapter of "gardener type" innovation policies in underdevelopment contexts.

Dessa forma, o conteúdo das políticas de promoção de um sistema nacional de inovação de um país em desenvolvimento deve buscar não somente o incentivo e a interação entre seus elementos constitutivos, mas, sobretudo, a construção de espaços e a criação de instituições que preencham tais lacunas institucionais. 


\section{Considerações Finais}

Diante do que foi exposto, verificou-se que a implementação efetiva e funcional do modelo da Tríplice Hélice no Brasil ainda encontra diversos obstáculos relacionados à organização e à estruturação dos detentores da infraestrutura de pesquisa nacional, que estão majoritariamente presentes no ambiente universitário, o que acaba por obstaculizar a interação desse ambiente junto ao setor produtivo. Isso porque as universidades pátrias acabam por ter que dividir seus recursos, equipamentos e corpo de funcionários com as atividades relacionadas ao ensino.

Consequentemente, e como restou bem ilustrado na pesquisa feita por Turchi e Arcuri (2017), junto aos responsáveis pelas principais infraestruturas públicas de pesquisa no Brasil, nota-se que para realizar pesquisas e projetos na indústria e transferir tecnologia para ela aplicar em sua produção e prestação de serviços, essas instituições ainda carecem de pessoal (tanto daquele responsável pelo suporte administrativo e monitoramento das parcerias como também de equipe técnica), de preparo e de expertise.

Essa questão, por sua vez, pode ser encarada como uma lacuna institucional, posto que o sistema de inovação acaba por não conseguir prover devidamente a interação de seus agentes e o consequente desenvolvimento socioeconômico pretendido, sendo essa uma situação que pode ocorrer principalmente com países em desenvolvimento (FELIPE, 2017, p. 19).

Por causa disso, é imperioso que se fomente a criação e o crescimento de espaços de inovação voltados à troca de conhecimento e ao esforço conjunto das partes que compõem a Tríplice Hélice, os quais são ocupados também por instituições secundárias, ou organizações híbridas, voltadas para a promoção de atividades científicas e tecnológicas em busca do desenvolvimento econômico e social (como centros de inovação, pré-incubadoras, incubadoras, aceleradoras, parques tecnológicos, núcleos de inovação tecnológica, entre outros).

Nesses locais, a atuação conjunta dessas organizações, da universidade, do Estado e das empresas pode prover outros meios de ocupar os espaços que a atuação de um dos membros da tríplice hélice deixa de ocupar, suprindo essa ausência.

Em outras palavras, e sob o prisma das universidades pátrias, para que essas instituições possam atuar junto ao setor produtivo e ter suas pesquisas aplicadas para a transformação da sociedade, é imperioso que elas ampliem sua interação junto aos habitats de inovação existentes e se esforcem para desenvolvê-los, a fim de que as demais organizações existentes nesse cenário possam ampará-las em sua nova função junto à sociedade.

\section{Referências}

ALBUQUERQUE, Eduardo da Motta. Sistema nacional de inovação no Brasil: uma análise introdutória a partir de dados disponíveis sobre a ciência e a tecnologia. Revista de Economia Política, São Paulo, v. 16, n. 3, p. 56-72, 1996.

AMIGO, Fernanda Vargas; GUZMÁN, Sócrates Jacobo Moquete. Incubadoras de empresas de base tecnológica como política de fomento à geração de inovação e riqueza na microrregião IlhéusItabuna. Cadernos de Prospecção, Salvador, v. 11, Edição Especial, p. 359-374, abr.-jun. 2018. 
AROCENA, R.; SUTZ, J. Innovation Systems and Developing Countries. DRUID Working Paper, Dinamarca, n. 2-5, 2002. Disponível em: https://ideas.repec.org/p/aal/abbswp/02-05.html. Acesso em: 20 jul. 2019.

BRASIL. Lei n. 10.973, de 2 de dezembro de 2004. Dispõe sobre incentivos à inovação e à pesquisa científica e tecnológica no ambiente produtivo e dá outras providências. Diário Oficial da União, Brasília, DF, 3 de dezembro de 2004. Disponível em: http://www.planalto.gov.br/ccivil_03/_Ato20042006/2004/Lei/L10.973.htm. Acesso em: 20 jul. 2019.

BRASIL. Lei n. 13.243, de 11 de janeiro de 2016. Dispõe sobre estímulos ao desenvolvimento científico, à pesquisa, à capacitação científica e tecnológica e à inovação e altera a Lei n. 10.973, de 2 de dezembro de 2004, a Lei n. 6.815, de 19 de agosto de 1980, a Lei n. 8.666, de 21 de junho de 1993, a Lei n. 12.462, de 4 de agosto de 2011, a Lei n. 8.745, de 9 de dezembro de 1993, a Lei n. 8.958, de 20 de dezembro de 1994, a Lei n. 8.010, de 29 de março de 1990, a Lei n. 8.032, de 12 de abril de 1990, e a Lei n. 12.772, de 28 de dezembro de 2012, nos termos da Emenda Constitucional n. 85, de 26 de fevereiro de 2015. Diário Oficial da União, Brasília, DF, 12 de janeiro de 2016. Disponível em: http://www.planalto.gov.br/ccivil_03/_Ato2015-2018/2016/Lei/ L13243.htm. Acesso em: 21 jul. 2019.

CASSIOLATO, José Eduardo. A economia do conhecimento e as novas políticas industriais e tecnológicas. In: LASTRES, Helena Maria Martins; ALBAGLI, Sarita (org.). Informação e globalização na era do conhecimento. Rio de Janeiro: Campus, 1999. p. 164-90.

CHAMPENOIS, Claire; ETZKOWITZ, Henry. From boundary line to boundary space: The creation of hybrid organizations as a Triple Helix micro-foundation. Technovation, Holanda, v. 76-77, p. 28-39, 2018.

CLOSS, Lisiane; FERREIRA, Gabriela Cardozo. Transferência de Tecnologia Universidade-Empresa: uma revisão das publicações científicas brasileiras no período 2005-2009. Gest. Prod., São Carlos, v. 19, n. 2, p. 419-432, 2012.

CUNHA, Bruno Queiroz. Uma análise da construção da agenda de inovação no setor público a partir de experiências internacionais precursoras. In: CAVALCANTE, Pedro et al. Inovação no setor público: teoria, tendências e casos no Brasil. Brasília: Enap: Ipea, 2017. p. 43-58.

DE NEGRI, Fernanda. Novos caminhos para a inovação no Brasil. Washington (EUA): Editora Wilson Center, 2018.

DE NEGRI, Fernanda. Por uma nova geração de políticas públicas de inovação no Brasil. In: TURCHI, Lenita Maria; DE MORAES, José Mauro (org.). Políticas de apoio à inovação tecnológica no Brasil: avanços recentes, limitações e propostas de ações. Brasília: Ipea. 2017.p. 25-46.

ETZKOWITZ, Henry; ZHOU, Chunyan. Hélice Tríplice: inovação e empreendedorismo universidadeindústria-governo. Estudos Avançados, São Paulo, v. 31, n. 90, p. 23-48, 2017.

FAIAD, Michele Mamede et al. Sistema Nacional de Inovação: uma Análise dos Sistemas na Alemanha e no Brasil. Navus - Revista de Gestão e Tecnologia, Santa Catarina, v. 6, p. 6-25, 2016.

FELDEN, Érico Pereira Gomes; MACHADO JÚNIOR, José Eduardo; TEIXEIRA, Clarissa Stefani. Habitats de inovação de Florianópolis: os ambientes que transformam o ecossistema de inovação e empreendedorismo. 2. ed. São Paulo: Perse, 2019. v. 2. 106p. 
FELIPE, Ednilson Silva. Schumpeter, os Neoschumpeterianos e as Instituições: o conceito e o papel numa economia dinâmica e globalizada. In: XII CONGRESSO BRASILEIRO DE HISTÓRIA ECONÔMICA E $13^{a}$ CONFERÊNCIA INTERNACIONAL DE HISTÓRIA DE EMPRESAS. 2017. Rio de Janeiro. Anais [...], Rio de Janeiro: UFF/ABPHE, 2017.

FERREIRA, Camila Lisdália Dantas. A hélice tríplice e a universidade de Brasília: as atividades de transferência de tecnologia conduzidas pelo núcleo de inovação tecnológica. 2018. $119 f$.

Dissertação (Mestrado em Propriedade Intelectual e Transferência de Tecnologia para Inovação) Universidade de Brasília, Profnit, Brasília, 2018.

FINEP - FINACIADORA DE ESTUDOS E PROJETOS. Manual de Oslo: diretrizes para a coleta e interpretação de dados sobre inovação tecnológica. 3. ed. Brasília, DF: FINEP, 2005. Disponível em: http://download.finep.gov.br/imprensa/manual_de_oslo.pdff. Acesso em: 26 maio 2019.

GIMENEZ, Ana Maria Nunes; BONACELLI, Maria Beatriz Machado; CARNEIRO, Ana Maria. A Universidade em um contexto de mudanças: integrando ciência, tecnologia e inovação. Revista de Propriedade Intelectual - Direito Contemporâneo e Constituição, São Paulo, v. 10, p. 115133, 2016.

IPIRANGA, Ana Silvia Rocha; HORA, Priscilla Corrêa. O tipo de pesquisa e a cooperação universidade, empresa e governo: uma análise na rede nordeste de biotecnologia. Organizações \& Sociedade, Bahia, v. 19, p. 17-34, 2012.

JOHNSON, Björn; LUNDVALL, Bengt Åke. Promoting Innovation Systems as a Response to the Globalising Learning Economy. In: SEMINÁRIO INTERNACIONAL ARRANJOS PRODUTIVOS LOCAIS E NOVAS POLÍTICAS DE DESENVOLVIMENTO INDUSTRIAL E TECNOLÓGICO. 2000. Rio de Janeiro. Nota Técnica n. 4, Rio de Janeiro: Redesist, 2000.

MACHADO, Andréia de Bem; SILVA, Andreza Regina Lopes da; CATAPAN, Araci Hack. Bibliometria sobre concepção de habitats de inovação. Navus - Revista de Gestão e Tecnologia, Santa Catarina, v. 6, p. 88-96, 2016.

MANSANO, Fernanda Helen. Avaliação das incubadoras de empresas de base tecnológica do Paraná a partir de um modelo proposto. 2016. 100f. Dissertação (Mestrado) - Programa de PósGraduação em Ciências Econômicas, Universidade Estadual de Maringá, Maringá, 2016.

MANSANO, Fernanda Helen; PEREIRA, Marcelo Farid. Business incubators as support mechanisms for the economic development: Case of Maringa's Technology Incubator. International Journal of Innovation, São Paulo, v. 4, p. 23-32, 2016.

MANSANO, Fernanda Helen; PEREIRA, Marcelo Farid; PARRE, José Luis. Classificação das Incubadoras de Empresas de Base Tecnológica do Paraná utilizando a análise fatorial. In: 26 CONFERÊNCIA ANPROTEC, 2016, Fortaleza. Anais [...], Fortaleza: ANPROTEC, 2016, p. 50-75.

MARCOVITCH, J. A cooperação da universidade moderna com o setor empresarial. Revista de Administração, São Paulo, v. 34, n. 4, p. 13-17, 1999.

OSINSKI, Marilei et al. A Presença dos Papéis Organizacionais da Tríplice Hélice em um Núcleo de Inovação Tecnológica da Região Sul do Brasil. In: VIII CONGRESSO INTERNACIONAL DE CONHECIMENTO E INOVAÇÃO, Guadalajara, México, 2018. Anais [...], Guadalajara (México): ciKi, 2018.

PRESTES, Gabriel Prestes et al. Inovação no Brasil e sua Relação com a Tríplice Hélice Universidade. In: XVII MOSTRA DE INICIAÇÃO CIENTÍFICA, PÓS-GRADUAÇÃO, PESQUISA E 
EXTENSÃO, Caxias do Sul, 2017. Anais [...], Caxias do Sul: UCS, 2017.

SARTORI, Viviane. In Hab-Read-IHR: metodologia de leitura de entorno para habitats de inovação. 2007. 489 f. Tese (Doutorado Engenharia e Gestão do Conhecimento) - Programa de Pós-Graduação em Engenharia e Gestão do Conhecimento (ECG), Universidade Federal de Santa Catarina, Florianópolis, 2017.

SEVERINO, Antônio Joaquim. Metodologia do trabalho científico. 23. ed. rev. e atual. São Paulo: Cortez, 2007.

TEIXEIRA, C. S. et al. Habitats de Inovação: alinhamento conceitual. Perse Editora, 2016.

Disponível em: http://via.ufsc.br/download-habitats-de-inovacao/. Acesso em: 27 jul. 2019.

TERRA, Edson Azevedo Filho et al. O modelo da tripla hélice e o desenvolvimento regional: um estudo de caso sobre o setor metalmecânico em Campos dos Goytacazes, RJ. Linkscienceplace Interdisciplinary Scientific Journal, Rio de Janeiro, v. 5, p. 1-17, 2018.

TURCHI, Lenita Maria; ARCURI, Marcos. Interação Institutos Públicos de Pesquisa e empresas: Avaliação das parcerias. In: TURCHI, Lenita Maria; DE MORAIS, José Mauro (org.). Políticas de apoio à inovação tecnológica no Brasil: avanços recentes, limitações e propostas de ações. Brasília: Ipea, 2017. p. 81-112.

\section{Sobre os Autores}

\section{Marcelo Farid Pereira}

E-mail: faridmarcelo@gmail.com

Professor nas áreas de Análise de Investimentos e Habitats de Inovação da UEM e do Programa de Pós-Graduação - Mestrado em Propriedade Intelectual e Transferência de Tecnologia para a Inovação (PROFNIT), Ponto Focal UEM.

Endereço profissional: Av. Colombo, n. 5.790, Jardim Universitário, Maringá, PR. CEP: 87020-900.

\section{Bruno Teixeira Maldonado}

E-mail: bruno.teixeira.maldonado@gmail.com

Aluno do Programa de Pós-Graduação - Mestrado em Propriedade Intelectual e Transferência de Tecnologia para a Inovação (PROFNIT), Ponto Focal Universidade Estadual de Maringá - UEM.

Endereço profissional: Av. Colombo, n. 5.790, Jardim Universitário, Maringá, PR. CEP: 87020-900. 